\title{
RELUTÂNCIA ÀS VACINAS E AMEAÇA AO PROGRESSO NO COMBATE À DOENÇAS IMUNOPREVENÍVEIS: REVISÃO BIBLIOGRÁFICA
}

\author{
Ramon Gomes da Silva'; Maria Eduarda Silva Gouveia ${ }^{1}$; Beatriz Carneiro Miranda de \\ Araújo' ${ }^{1}$; Mariana Nathália Gomes de Lima². \\ ${ }^{1}$ Graduando(a) em Nutrição, Centro Universitário Brasileiro (UNIBRA), Recife, PE. \\ ${ }^{2}$ Sanitarista, Centro Universitário Brasileiro (UNIBRA), Recife, PE.
}

DOI: 10.47094/IICNNESP.2021/37

\section{RESUMO}

A saúde pública brasileira tem sofrido consequências irreparáveis ante o cenário pandêmico da COVID-19, ameaçando a credibilidade mundial do Sistema Único de Saúde na organização de campanhas de imunização, e ainda, sua garantia operacional pela falta de investimentos. Atitudes negacionistas e motins antivacina aportados pelo governo atual, além da aversão à ciência e a sobrecarga do sistema de saúde são situações desfavorecedoras. Buscas nas bases de dados Scielo e PubMed orientaram essa revisão narrativa, alinhando-se ao objetivo de delinear a correlação entre a pandemia e os prejuízos causados à qualidade dos serviços de saúde no Brasil. Para esse estudo foram selecionadas pesquisas publicadas, excluindo-se às que não apresentaram evidências de carácter científico. Os achados também revelaram preocupações no que tange ao teor e segurança das informações repassadas pelas mídias sociais. Diante disso, propõe-se uma reflexão da postura a ser tomada em defesa dos direitos e garantias à saúde de qualidade.

PALAVRAS-CHAVE: Coronavírus. Pandemia. Saúde Pública.

ÁREA TEMÁTICA: Política e gestão em Saúde.

\section{INTRODUÇÃO}

Com aproximadamente 17,2 milhões de infectados pelo novo coronavírus e cerca de 480 mil óbitos em 09 de junho de 2021, o Brasil se consolida como um dos países mais afetados no cenário global desde a primeira notificação em 26 de fevereiro de 2020 (BRASIL, 2020). Para além, esses dados apontam ainda o reflexo da postura adotada na gestão da crise sanitária que vem acarretando ao país graves consequências, que poderiam ter sido evitadas com a adoção de medidas de contenção já nas primeiras semanas de evolução da pandemia, intensificando-se a Vigilância Epidemiológica (VE) no enfrentamento do vírus. Para Mota e Teixeira (2020) a existência de um sistema nacional, universal e gratuito como o Sistema Único de Saúde (SUS), que oferta grande cobertura da Atenção Primária à Saúde e inclui em muitas áreas a Estratégia de Saúde da Família, e por garantir eficientes ferramentas de vigilância epidemiológica capazes de atingir todos os estados e municípios, a sociedade brasileira teria todo o suporte necessário para o enfrentamento dessa crise sanitária que se alastra por 
todo território nacional. Apesar disso, o que se vê é uma negligência governamental ancorada num negacionismo que tem comprometido investimentos em pesquisas e iniciativas eficazes no combate à pandemia em curso.

Outro ponto que vale ressaltar nessa narrativa, refere-se à facilidade em acessar ou receber informações midiáticas nos tempos atuais. Muitas vezes, a não checagem dos fatos pode acarretar em interpretações sensacionalistas, falsas ou imprecisas, provocando uma série de reações equivocadas como as que surgiram em torno da oferta de vacinas. Tal contexto retrata sentidos sociais da rede semiótica, dinamizada pela interdiscursividade do intercurso da pandemia atual, valendo-se do detrimento de Fake News e descréditos de falas moldadas (SILVA; DOS SANTOS; DE OLIVEIRA, 2020). O que se impõe nessa conjuntura não é só o que se refere ao período agudo que atravessamos, mas os problemas crônicos que nos assolam nos últimos tempos e que dizem respeito à função dos Estados (e a quem servem) e dos pactos solidários das políticas sociais (SILVEIRA; GONÇALVES, 2020).

\section{OBJETIVO}

Promover uma discussão a respeito da credibilidade e urgência das campanhas de vacinação, indispensáveis na prevenção e combate às doenças e surtos, como o que estamos enfrentando.

\section{METODOLOGIA}

O presente trabalho caracteriza-se como uma pesquisa de revisão bibliográfica do tipo narrativa, a fim de reunir estudos para aporte teórico e discursivo em diferentes bases de dados eletrônicas, tendo sido consultadas: Scielo e PubMed. Os artigos e dados obtidos foram selecionados no período de 18 maio a 06 de junho por meio dos seguintes descritores: "Coronavírus", "Vacina", "Pandemia", "SUS" "Vigilância epidemiológica", resultando em 15 achados, dentre os quais destacamos sete para inclusão por serem consideradas publicações com temas pertinentes ao objetivo proposto, excluindo os artigos que não apresentavam relação com a temática, e ainda, por não apresentarem evidências de carácter científico.

\section{FUNDAMENTAÇÃO TEÓRICA}

No Brasil, o discurso do governo é um desafio para o combate à pandemia da COVID-19, pois contraria todas as recomendações preconizadas pela Organização Mundial da Saúde (OMS), uma vez que fortalece a hesitação da população à vacinação, exaltando o uso de medicamentos ineficazes no tratamento da doença, compartilhando informações falsas, além de destinar recursos financeiros a esses medicamentos sem nenhuma eficácia comprovada (MATOS; BARBIERI; COUTO, 2020). Outro ponto grave que podemos citar é a falta de apoio financeiro aos estudos científicos e o subfinanciamento crônico do Sistema Único de Saúde (SUS) que já perdura por anos, agravando 
ainda mais o cenário atual que vivemos. Só em 2019 o SUS perdeu R \$ 20 bilhões com a Emenda de Tetos de Gastos (PEC-95), que vem agravando a saúde financeira do sistema há mais de duas décadas (COSTA et al, 2020). Ainda assim, o SUS resiste frente à pandemia do novo coronavírus, atendendo e promovendo saúde a mais de 100 milhões de brasileiros cadastrados no sistema e, através das unidades de Atenção Primária à Saúde (APS) é priorizada a continuidade de ações preventivas de saúde pública (como a vacinação da população, por exemplo), vista como porta de entrada para casos suspeitos de Covid-19 (DAUMAS et al, 2020). Estudos propostos por Matos et al. (2020) afirmam que para atingir uma alta cobertura de vacinação deve-se ter uma maior atenção comunitária nas Unidades Básicas de Saúde (UBS) e mais capacidade de coordenação, ou seja, a falta de coordenação entre o governo federal e os governadores dos outros 26 estados brasileiros revela divergências na resposta ao combate da pandemia no Brasil, o que implica em baixas taxas de vacinação. Assim, o país vive uma crise sanitária, humanitária e política ao mesmo tempo. Apesar das políticas nacionais irresponsáveis, com posição negacionista, o Brasil atualmente faz parte do programa Covax Facility (um mecanismo global para aquisição conjunta e distribuição equitativa de vacinas para a COVID-19) e conta com algumas vacinas aprovadas pela ANVISA, como: Oxford/AstraZeneca/Fio Cruz com $80 \%$ de eficácia com intervalo de três meses entre as duas doses; Sinovac/Butantan com 50,38\% (eficácia global); 78\% em casos leves; 100\% em casos graves e moderados; e a Pfizer/BioNTech com 95\% de eficácia (SATIE, 2020). Por fim, a minimização da pandemia e a descrença na ciência por parte do governo é uma ameaça a credibilidade do Programa Nacional de Imunização (PNI), que se encontra consolidado no país há quase 5 décadas. O PNI luta junto ao SUS nesse cenário, com sua vasta experiência em campanhas de vacinação em massa, oferecendo vacinas gratuitas e universais, além de estabelecer calendário nacional, considerado um dos mais extensos do mundo, promovendo a equidade em saúde (MATOS; BARBIERI; COUTO, 2020). Porém, a negação cientifica adotada pelo governo também ameaça a sua alta área de cobertura, os números de vacinação poderiam ser muito maiores no país se não fosse a abordagem equivocada e a desaceleração da vacinação diante da pandemia que tem persistido em continuar vitimando milhões de brasileiros.

Além disso, existe uma preocupação em relação às mídias sociais nesse momento pandêmico, dado a facilidade de acesso aos meios de tecnologia e comunicação, onde informações não fundamentadas são repassadas e compartilhadas sem que haja uma verificação da veracidade das mesmas, gerando assim, comportamentos prejudiciais à saúde psicossocial da população, como por exemplo, o aumento no número de casos de ansiedade e depressão (SILVA; DOS SANTOS; DE OLIVEIRA, 2020). De tal modo, a divulgação equivocada de informações sem embasamento científico vem contribuindo para gerar relutância às vacinas.

\section{CONSIDERAÇÕES FINAIS}

É consideravelmente incompatível lidar contra uma pandemia de forma unitária, por isso, cientistas e pesquisadores trabalham incessantemente para garantir vida a população através da ciência com embasamento. A cada dia uma nova doença surge e, olhando para décadas anteriores, sem os movimentos pró vacina não existiria compatibilidade com a vida no mundo de hoje, tendo em 
vista inúmeras epidemias virais e bacterianas, as quais sem vacina já teriam erradicado a humanidade. A postura do atual governo, ao militar contrariamente à campanha de vacinação contra o novo coronavírus, dando ênfase e visibilidade ao movimento antivacina através das mídias, propagando notícias e dados incoerentes, tornando uma pequena parte da população insegura e ainda resistente para a consolidação do movimento, reflete uma atitude errônea e irresponsável. É mais agravante ao considerarmos o que garante a Constituição Federal (1988) ao declarar que a "A saúde é direito de todos e dever do estado". Com isso, refletimos que o SUS é incapaz de prezar pela vida de forma unilateral, pois não tem o poder administrativo em suas mãos.

\section{PRINCIPAIS REFERENNCIAS}

BRASIL, Ministério da Saúde, Secretaria de Vigilância em Saúde. Boletim Epidemiológico Especial 52. Doença pelo Coronavírus COVID-19. Brasília, DF. 7 de maio de 2021, 85 páginas. Disponível em:https://www.gov.br/saude/pt-br/coronavirus/boletins-epidemiologicos/boletim-epidemiologicocovid-19-no-52.pdf/viewCOVID-52.pdf. Acesso em: 09 de maio de 2021. 2021.

BRASIL, Presidência da República. Constituição da República Federativa do Brasil: promulgada em 5 de outubro de 1988. Brasília: Senado Federal, 1988. Disponível em http://www. planalto.gov. br/ccivil_03/constituicao/constituicao.htm. Acesso em 04/06/2021.

COSTA, Ana Maria; RIZZOTTO, Maria Lucia; LOBATO, Lenaura. Na pandemia da Covid-19, o Brasil enxerga o SUS. Rio de Janeiro, v. 44, n. 125, p. 289-296, ABR-JUN 2020. DOI: 10.1590/01031104202012500 .

DAUMAS, Regina Paiva; SILVA, Gulnar Azevedo e; TASCA, Renato; LEITE, Iuri da Costa; BRASIL, Patricia; GRECO, Dirceu B.; GRABOIS, Victor; CAMPOS, Gastão Wagner de Souza. A bipolaridade da crise sanitária: sofismas economicistas e impactos sociais na pandemia do coronavírus. Revista de Saúde Coletiva, Rio de Janeiro, v. 30(2), e300212, 2020 DOI https://doi. org/10.1590/S0103-73312020300212.

MATOS, Camila; BARBIERI, Carolina Luísa; COUTO, Marcia Thereza. Covid-19 and its impact on immunization programs: reflections from Brazil. Rev. de Saúde Pública. 2020;54:114.DOI: https://doi.org/10.11606/s1518-8787.2020054003042.

MOTA, Eduardo; TEIXEIRA, Maria Glória. Vigilância epidemiológica e a pandemia da Covid-19 no Brasil. Elementos para entender a resposta brasileira e a explosão de casos e mortes. Saúde em debate, 2020. DOI: 10.1590/SciELOPreprints.1317.

SATIE, Anna. Saiba qual é a eficácia das principais vacinas contra a Covid-19. CNN Brasil. São Paulo, 12 de jan. de 2021. Disponível em: https://www.cnnbrasil.com.br/saude/2020/12/08/qual-a-eficacia-das-principais-vacinas-contra-a-covid-19. Acesso em: 02 de mai. 2021.

SILVA, Hengrid Graciely Nascimento; DOS SANTOS, Luís Eduardo Soares; DE OLIVEIRA, Ana Karla Sousa. Efeitos da pandemia no novo Coronavírus na saúde mental de indivíduos e 
coletividades/Effctsofthe new Coronavirus pandemic on the mental health of individual sand communities. Journal of Nursing and Health, v. 10, n. 4, 2020.

SILVEIRA, Márcia Ney; GONÇALVES, Carlos Alberto Grisólia. A bipolaridade da crise sanitária: sofismas economicistas e impactos sociais na pandemia do coronavírus. Physis: Revista de Saúde Coletiva, Rio de Janeiro, v. 30(2), e300212, 2020 DOI: http://dx.doi.org/10.1590/S010373312020300212. 